\title{
Strengthening European Identity by promoting multilingualism in education
}

\author{
Gabriela DOMILESCU・ \\ Cosmina Simona LUNGOCI
}

\section{Abstract}

Actual understanding of multilingualism refers to the ability of individuals to consistently use two or more languages in communication. Knowing several languages facilitates international mobility and cooperation, fosters educational and professional integration, strengthens people's belonging to the European community as European citizens. Many European citizens are motivated to study another foreign language because of multiple reasons, especially the personal and professional advantages of language skills. However, it is also important to understand why many others are not currently studying foreign languages or are limited to the knowledge of English as second language. Some may consider foreign languages not to be essential for their lives, others may consider teaching methods too academic, rigid, less attractive, too boring, other may be traumatized by their school experiences. Whatever the reasons, solutions must be found to overcome these hesitations and learning fears. The purpose of these study is to investigate students' representations (future teachers) on European multilingualism and their attitudes towards the acquisition, knowledge and practicing of foreign languages in Europe. In order to establish the theoretical framework of our research, we have reviewed official studies elaborated by the European Commission, specialized articles and papers addressing the issue of multilingualism in European context. Using a questionnaire based research we aimed to identify students' (future teachers) reasons for choosing the study of a foreign language; the extent to which students know and exploit the benefits of European multilingualism and how they think it could be promoted by them, as future teachers. In line with the results of our research, we intend to we intend to highlight ways of promoting multilingualism in education.

Key words: education, foreign language, multilingualism, teacher training

\section{Introduction}

According to the Special Eurobarometer 386, Europeans and their languages,

2012 (http://ec.europa.eu/public_opinion/index_en.htm), 54\% of Europe's citizens speak another language than their mother tongue at conversational level and $88 \%$ of them think that speaking a second language brings benefits to personal development.

- Gabriela Domilescu - Ph.D., Teacher Training Department, West University of Timisoara, gabriela.domilescu@e-uvt.ro

- Cosmina Simona Lungoci - Ph.D., Teacher Training Department, West University of Timisoara, cosmina.lungoci@e-uvt.ro 
Motivation lies at the basis of thorough learning and knowing of foreign languages. Many European citizens are already convinced and motivated to study another foreign language because of multiple reasons, especially the personal and professional advantages of language skills. However, it is also important to understand why many others are not currently studying foreign languages or are limited to the knowledge of English as second language. Some may consider foreign languages not to be essential for their lives, others consider teaching methods too academic, rigid, less attractive, too boring, other may be traumatized by their school experiences. Whatever the reasons, solutions must be found to overcome these hesitations and learning fears. By making this process a more enjoyable activity, we can hope that people will understand the personal benefits of language use.

The term of European identity carries within complex and problematic characteristics, which are in constant evolution and development. The development of a European identity implies the existence of a process of identification of people with the European Union, a sense of belonging to European history and its influence on the opinions and behaviours of European citizens. Numerous studies have shown that selfidentification as a European is based, first and foremost, on feelings of national belonging. Therefore, the national identity is not contradictory with the feeling of belonging to the European Union, but, on the contrary, it is complementary: everything that can be observed by analysing the relationship with the European project is built in relation to the nation. Therefore, identity means both similarity and differentiation, objectivity and subjectivity; individuality and colectivity/community; permanence, contextuallity, and transformation. Therefore, a European identity remains still dual, the national consciousness coexisting with the European one. Even if we live with "two identities", the uniqueness can be preserved while promoting common interests (Tartler, 2006).

One of the characteristics of European identity is speaking mostly Indo-European languages. The linguistic diversity within the EU is considered to be "the cultural and democratic vault of the European Union and an essential brand of European identity" (Tartler, 2006, p.88). Within the context of linguistic diversity, we approach the concept of multilingualism from two perspectives: one of Anglo-Saxon inspiration (within the society, several communities coexist, spirited by identity feelings, speaking regional and minority languages, against and not together with the official European languages); the other meaning has its source in the European humanism, referring to open societies, which communicate and intertwine to create new identities, while preserving their own identity and contributing to its development (Negrescu-Babuș, 2015). This is the approach we embrace in the present paper: „multilingualism is understood as the ability of societies, institutions, groups and individuals to engage, on a regular basis, with more than one language in their day-to-day lives"(European Commision, 2007). A narrow understanding of multilingualism reffers to the alternative use and knowledge of several languages; broadly it refers to the alternative use of several linguistic systems, regardless of their status. 


\section{Methodology}

The benchmarks from the specialized literature on multilingualism guided us in organizing the research methodology: we consulted documents elaborated by the European Commission, articles and specialized volumes that address the issue of multilingualism in the European context. The research question of these study is: What are (future teachers) students' representations on European multilingualism and their attitudes towards the acquisition, knowledge and practicing of foreign languages in Europe? Accordingly, the objectives of our study are:

- to identify students' representations (future teachers) on European multilingualism and the subsequent advantages;

- to explore students' representations regarding the way teachers could promote European multilingualism

- to analyze possible connections between students' level of language knowledge and their attitudes towards multilingualism as future teachers;

- to highlight ways of promoting multilingualism in education.

In order to realize the above objectives, we used a questionnaire based survey. The questionnaire was addressed to the 1st year students of the Faculty of Letters of the West University of Timisoara (various specializations: Romanian, English, German) enrolled in the Teacher Training Programme and to the 1st year students from Pedagogy of preschool and primary education (the Faculty of Sociology and Psychology). The sample consisted of 112 students, 97\% female and 3\% male, 58\% from urban areas and 42\% from rural areas. As the age, the vast majority (55\%) of the respondents are 19 years old, $30 \% 20$ years old, $3 \% 21$ years old, and $12 \%$ over 21 years old (Pedagogy of preschool and primary education students who are already teachers in primary education or kindergarden). From the total number of students, 35\% follow the study of foreign languages within the Faculty of Letters and 65\% are students at Pedagogy of preschool and primary education. We chose to apply the questionnaire to students from these two faculties because their graduates have the greatest chance to work in education as teachers in kindergarden, primary school and in secondary and high school(teaching Romanian and foreign languages).

The questions addressed to students were ment to: (a) identify what multilingualism means to them, (b) identify the advantages of knowing foreign languages; (c) shape an image about their opinion on how European multilingualism could be promoted from the position of future teachers, (d) establish the reasons they would recommend the study of a certain foreign language.

All information from the answers to these questions acquires an added value when correlated with the linguistic level of respondents and with their own possibility of choosing the foreign language they have studied. The factual questions of the questionnaire referred to: the age and sex of the respondents, the environment of origin 
and their specialization.Through the questions of our questionnaire we wanted to identify the following elements, which we will detail below:

- how many foreign languages students know and the level of proficiency they have: $20.6 \%$ of students know a single foreign language; $59.7 \%$ of students know two foreign languages and $19.7 \%$ of students know three or more foreign languages

- regarding students language level, the results are the following: 56\% - A1/A2, $87 \%-\mathrm{B} 1 / \mathrm{B} 2,37 \%-\mathrm{C} 1 / \mathrm{C} 2$

- 96\% of respondents know English, 49\% French, 27\% German, 13\% Spanish and 11\% Italian. Other languages obtained 6 percents, here students mentioning: Croatian, Portuguese, Arabic, Czech, Russian, Hungarian and Bulgarian languages, which they learned either from their family or because they lived in another country.

- the possibility of choosing the study of foreign languages: $42 \%$ of the respondents chose the languages they studied and $42 \%$ have learnt the language their school offered, generally English or French. In the case of $11 \%$ of them, the decision belonged to the parents and $8 \%$ of them learned the language of the country where they or their parents emigrated.

- the criteria for choosing / recommending the study of a foreign language. The vast majority of respondents (82\%) would choose or recommend the study of a foreign language depending on how often it is used internationally, 22\% depending on how easy it is to learn and only $8 \%$ in depending on how similar it is to the mother tongue; $7 \%$ of the respondents listed other reasons, almost all referring to the needs, wishes and interests of the respective person for a certain language and culture, but also the benefits that knowing a specific language could generate.

- ways to promote European multilingualism from a teaching position. $69 \%$ of the respondents consider that they could promote multilingualism as future teachers through formal and extracurricular activities (cultural events focused on music, literature, drama or foreign film, holidays abroad, twinning activities or volunteering abroad) that could help students to become familiar with other languages and cultures; $30 \%$ of the respondents consider they could promote multilingualism by knowing and using several foreign languages and 33\% recomending to students to learn foreign languages from the earliest age. A significant number of respondents also mentioned other variants (trips in foreign countries, meetings/conferences with writers/personalities form other countries, reading books in foreign languages, film festivals, visiting ethnic communities, partenerships with schools from other countries, multietnic festivals, cultural events). 


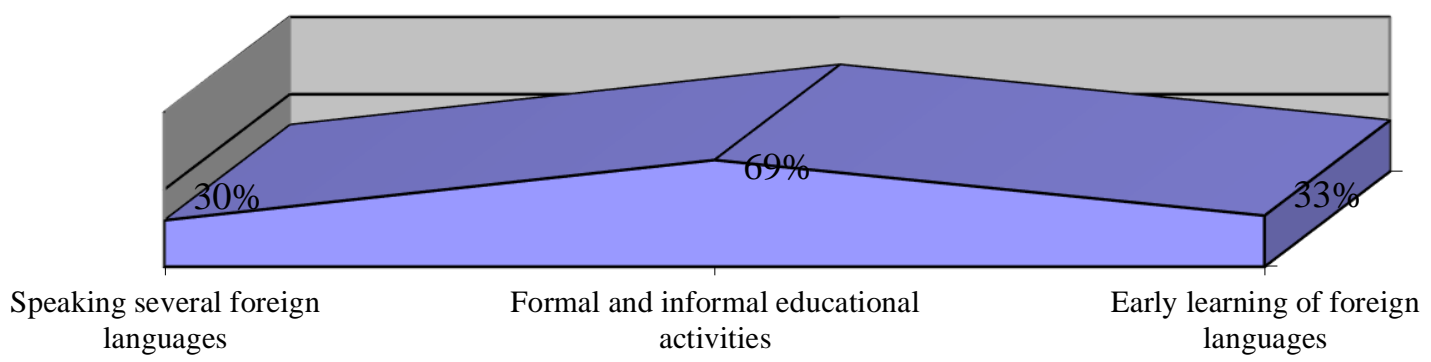

Figure 1: Ways to promote European multilingualism

Regarding the reasons involved in the study of foreign languages, $64 \%$ of the respondents learned or are currently learning a foreign language in order to use it in their professional activity and 65\% in order to use it in their personal life. On the third and fourth places, with similar values, we find the help foreign languages (will) represent in obtaining a job (33\%) and in discovering new cultures (30\%). 13\% of the students study foreign languages to settle in a foreign country and only $8 \%$ of them studied or are currently learning a foreign language in order to study abroad. 3\% of our respondents affirm they learn foreign languages to impress the people around them. $16 \%$ of students mention that the study and mastering of a foreign language positively influence their self -esteem and decision making abilities, which proves that, at least, a part of students is aware of the transversal competences involved in foreign language learning.

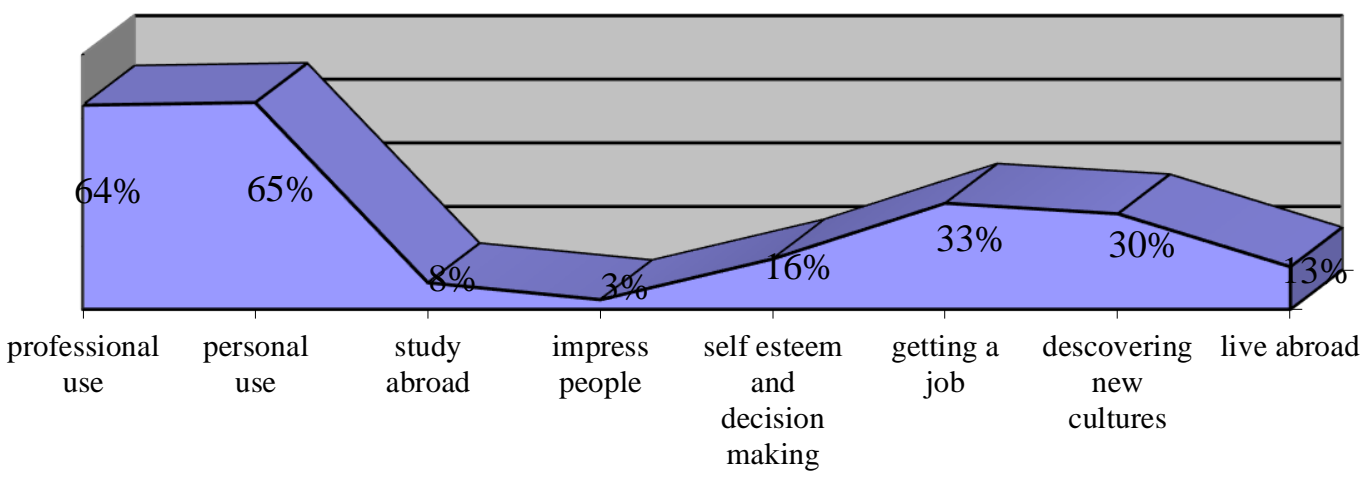

Figure 2: Reasons involved in the study of foreign languages

When asked to define the notion of multilingualism, students firstly associated it with the ability of a person to use several languages, secondly with the alternative use of several languages, the third and fourth place, with similar values, belonging to the coexistence of several communities in a given geographical area and the 
coexistence of several languages within a social group. For reasons of scientific rigor, we present the results obtained by reference to the weighted average.

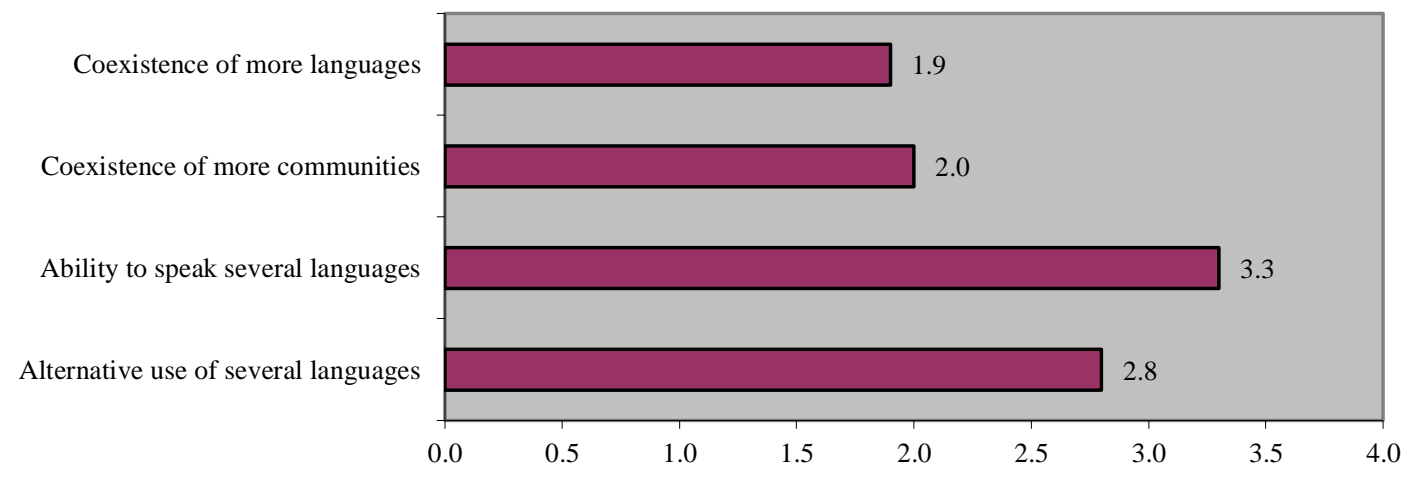

Figure 3: Multilingualism

In the opinion of our respondents, the advantages of multilingualism are: access to several linguistic communities and access to more information (with similar values 3.7 and 3.8). On the third and fourth place we find the possibility of communicating with more people and the increasing value of communication skills on the labor market. On the last place, students mention the fact that multilingual people have a higher concentration capacities, focusing better on their tasks.

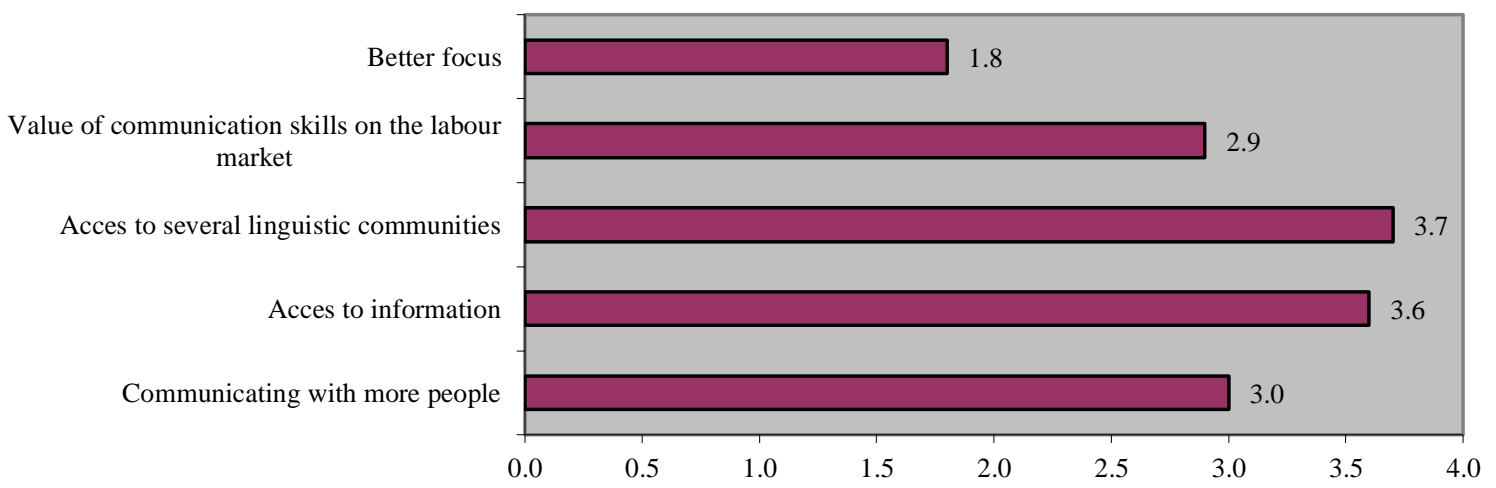

Figure 4: Advantages of multilingualism

\section{Results and discussions:}

Analysing the information that emerged from the questionnaire, we observe that students who speak two languages ( $87 \%$ of them) are independent users, in other words, they know the two foreign languages at intermediate level (B1/B2). As expected, English ranks first, followed by French and future teachers have the ability to use foreign languages in authentic communication situations. According to the Common European Framework of reference for language learning, teaching and assessment, students with B1/B2 level have the following competences in the communication plan: can understand the main points of clear standard input on familiar matters regularly encountered in 
work, school, leisure, etc. or ideas of complex text on both concrete and abstract topics, including technical discussions in his/her field of specialisation; can deal with most situations likely to arise whilst travelling in an area where the language is spoken and can interact with a degree of fluency and spontaneity that makes regular interaction with native speakers quite possible without strain for either party; can produce simple connected text on topics which are familiar or of personal interest (B1) and can produce clear, detailed text on a wide range of subjects and explain a viewpoint on a topical issue giving the advantages and disadvantages of various options (B2); can describe experiences and events, dreams, hopes and ambitions and briefly give reasons and explanations for opinions and plans (European Commision, 2001).

Most respondents (82\%) would choose or recommend the study of a foreign language depending on how often it is used internationally, which proves students interest for intercultural dialogue.The stated intention of future teachers to promote multilingualism in the didactic and extracurricular activities through cultural events focused on music, literature, drama or foreign film, holidays abroad, but also through the knowledge and use by themselves of several foreign languages supports the idea that education is a form of dissemination of multilingualism. The fact that future teachers speak up to three foreign languages, having varying levels of knowledge (noticing in our research a general intermediate level B) is an argument in favor of their positive attitude towards promotion of multilingualism, besides the various recommendations they make regarding their intention to promote the acquisition of foreign languages. Therefore, we can argue that there is a connection between students' level of language knowledge and their attitudes towards multilingualism as future teachers.Learning a language can be done in a variety of ways and at different levels of proficiency. Thus, outside school settings, more options are possible, depending on the goals we want to achieve.

The approach of languages in the European educational systems has always been important. "In Romania, the study of languages has always been officially encouraged, and, particularly, the knowledge of as many languages, at advanced performance levels, has represented an element of social prestige, which can be explained primarily by the relative zonal character of the use of Romanian language" (Carp, 2007, p.25). The spread of multilingualism requires a significant educational effort: it is essential that schools and educational institutions adopt a holistic approach to language teaching, by establishing appropriate links between mother tongue teaching and foreign language teaching(Orban, 2008). In Europe, linguistic diversity is a reality of daily life, due to the fact that in the 28 Member States, 23 official languages and 60 minority languages are used. In this context, learning English is a minimum requirement, but not a guarantee of the students' success in social life; learning two or more languages is a way to ensure a personal development favorable to the economic and social success of each one(Negrescu-Babuș, 2015).

Viewed from the perspective of multilingualism and diversity, the European identity has a great chance of affirmation through a developing dialogue within the value- 
generating diversity. The European Union also supports multilingualism through mobility programs designed for students since it allows them to study, train abroad, attend internships or volunteer, programs that contribute to the improvement of the languages they learn. Research shows that over $80 \%$ of students attending an Erasmus program have significantly improved their language proficiency (Agence Erasmus, 2018).

Valuing the recommendations of the Common European Framework of reference for language learning, teaching and assessment regarding multilingualism in education, the following aspects can be highlighted:

- multilingualism may be attained by simply diversifying the languages offered in schools or by encouraging pupils to learn more than one foreign language, or reducing the dominant position of English in international communication;

- the aim of language education is profoundly modified because it is no longer seen as simply to achieve 'mastery' of one or two, or even three languages, each taken in isolation, with the 'ideal native speaker' as the ultimate model; the aim is to develop a linguistic repertory, in which all linguistic abilities have a place.

Communication in foreign languages is one of the eight key competences of lifelong learning, necessary for personal fulfillment, active citizenship, social cohesion and employment in a knowledge-based society (Recommendation of the European Parliament and of the Council of 18 December 2006 on key competences for lifelong learning, 2006). Therefore, the ability to understand and communicate in several languages is a desirable skill for all European citizens. To achieve this goal, it is recommended to encourage people to become more open to other people's cultures / languages, to improve cognitive skills and to strengthen their mother tongue skills, as well as to exploit the opportunities to work or study in another Member State (European Commission, 2007).

In order to promote multilingualism in compulsory education, the curriculum should expand from a curriculum for each language taken in isolation to a curriculum for several languages, "in which linguistic knowledge (savoir) and skills (savoir-faire), along with the ability to learn (savoir-apprendre), play not only a specific role in a given language but also a transversal or transferable role across languages", which "implies progressive development of 'learning awareness' and the introduction of general language education which helps learners establish metacognitive control over their own competences and strategies" (European Commission, 2001).

As we have emphasized throughout our paper, in the actual European context, a central element of promoting democratic values and building European identity is education. The European identity is built daily and individually, and the educational context should give teachers motivating learning activities to contribute to the development of the awareness of belonging to the European community. Foreign languages and cultures are areas of essential knowledge in the construction of European 
identity, a complex and long-lasting process, which should be shaped from the earliest ages.

\section{References:}

Agence Erasmus+ France / Education Formation(2018).Bilan des projets Erasmus + sur l'enseignement et apprentissage des langues,http://www.agenceerasmus.fr/docs/2710_bilan-langues.pdf.

European Commission (2001).Common European Framework of reference for language learning, teaching and assessment.Cambridge University Press,https://rm.coe.int/16802fc1bf.

European Commission(2007). Commission of the European Communities, FINAL REPORT, High Level Group on Multilingualism. Office for Official Publications of the European Communities, https://eur-lex.europa.eu

Carp, R. (eds).(2007).Multilingvism și dialog intercultural în Uniunea Europeană. 0 viziune românească. București: Institutul European din România.

Duchesne, S. (eds). (2010), L`identité européenne, entre science politique et science fiction. Politique europénne. Paris: L`Harmattan, no. 30.

Herdina, P.-J. (2002).A dynamic model of multilingualism. Perspectives of change in psycholinguistics. Clevedon: Multilingual Matters, https://www.uibk.ac.at/anglistik/staff/herdina/kursunterlagen/dmm.pdf

Negrescu-Babuș, I. (2015).Aspecte actuale ale multilingvismului în contextul lingvistic european., Philologia, LVII, Academia de Științe a Moldovei.

Orban, L.(2008). Le multilinguisme en Europe, Revue internationale d'éducation de Sèvres [on line], http://journals.openedition.org/ries/358

Tartler, G. (2006). Identitate europeană. București: Editura Cartea Românească.

Recommendation of the European Parliament and of the Council of 18 December 2006 on key competences for lifelong learning (2006/962/EC), https://eurlex.europa.eu/legal-content/RO/TXT/?uri=celex:32006H0962 